\title{
AMERICAN NURSE-MIDWIFERY: A PROFESSIONAL MODEL FROM THE UNITED KINGDOM AND A POSSIBLE MODEL FOR CHINESE MIDWIFERY
}

\author{
Cecilia Jevitt ${ }^{*} \&$ Qiong Zheng ${ }^{* *}$
}

\begin{abstract}
Midwifery skills in the US were preserved through the era of birth hospitalization by nurse-midwives using an education and practice model based on British post-nursing registration midwifery. The largest group of midwives practicing in the US, certified nurse-midwives, maintained the nurse-midwifery model while British midwifery separated from nursing to match direct entry midwifery models in the European Economic Community. The midwifery model of care, which views menarche, pregnancy, birth and menopause as physiological, culture-bound processes that need supportive caring, is opposed to the biomedical model which views these as periods of illness and risk needing correction. By becoming adept at the use of medical technology, US nurse-midwives adapted practice to gaps in care by expanding scope of practice to include gynecology, birth control prescription, perimenopausal care, and well-woman primary care. Like US midwifery, Chinese midwifery professionalized through increasing education and scope of practice. China faces unmet midwifery and women's healthcare needs with its change to a two child policy. This paper describes a midwifery model that is cost-effective in clinician education and practice that China might adapt to meet its increasing women's healthcare needs.
\end{abstract}

INTRODUCTION

I. LITERATURE REVIEW: THE RE-PROFESSIONALIZATION OF MIDWIFERY IN THE US THROUGH A NURSE-MIDWIFERY MODEL BASED ON BRITISH

MIDWIFERY

II. CHINESE MidWIFERY: From TRADITION TO WESTERN INFLUENCE .......719

III. AdAPting the BRITISH MidWIFERY MOdEL TO AMERICAN CUlture. 720

IV. INCREASING THE SCOPE OF US MIDWIFERY PRACTICE ....................... 723

V. RENAISSANCE IN CHINESE MIDWIFERY FOLLOWING RECESSION AND

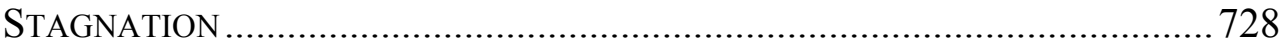

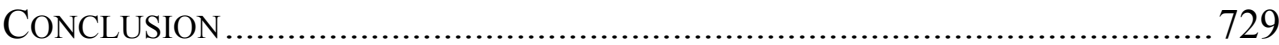

\footnotetext{
* Associate Professor, Yale School of Nursing, 400 West Campus Drive, West Haven, Connecticut, USA, 06477. Research fields: Midwifery Workforce Issues, Prenatal Weight Gain, Obesity in Pregnancy.

** Director, Bachelor of Science in Midwifery Program, Wenzhou Medical University, Chashan University Town, Wenzhou, Zhejiang, 325035, China. Research fields: Core Competencies in Midwifery Education, Simulation in Midwifery Education, Problem Based Learning.
} 


\section{INTRODUCTION}

Midwifery in the United States grew from a handful of nurse-midwives in 1925 to more than 11,000 in $2015 .{ }^{1}$ This article describes the cultural reestablishment of midwifery as a profession in the US and its scope of practice growth over the last 30 years. Nurse-midwifery has incorporated emerging technologies while maintaining traditional, low technology skills to become a holistic profession that provides a full range of women's health services. Chinese midwifery has potential for growth and may be able to use nurse-midwifery in the US as a model for development.

\section{LiterATURE REVIEW: THE RE-PROFESSIONALIZATION OF MIDWIFERY IN THE US THROUGH A NURSE-MIDWIFERY MODEL BASED ON BRITISH MIDWIFERY}

Anthropology, midwifery and feminist literature well document the anti-midwifery movements by US physician groups starting in the $1800 \mathrm{~s}$, as physicians sought to professionalize medicine and secure regular incomes. Midwives were labeled uneducated, dirty and unsafe with states promulgating laws against midwifery practice. As the numbers of physicians increased, more medical education experiences within hospitals were needed. This combined with the belief that home birth was unsanitary and unsafe, pushed birth into hospitals. ${ }^{23}$

Mary Breckinridge, a visionary Kentuckian, witnessed nurse-midwives working in France and the United Kingdom during World War I, and saw midwifery care as a solution to the crushing maternal and infant morbidity and mortality in rural Kentucky where no formal care was available. Using the British model of post-nursing midwifery, Breckinridge reestablished professional midwifery in the US in 1925, by bringing four nurse-midwives from the United Kingdom to found the Frontier Nursing Service. ${ }^{4}$ Breckinridge, consistent with the British midwifery model of that era,

\footnotetext{
${ }^{1}$ American College of Nurse-Midwives. Essential Facts about Midwives (2016), http://www.midwife.org/Essential-Facts-about-Midwives (last visit October 12, 2016).

${ }^{2}$ A. Dalton. Moms, Midwives, and MDs: A Mixed-Methods Study of the Medicalization and Demedicalization of Childbirth (2009), available at http:/dukespace.lib.duke.edu/dspace/bitstream/handle/10161/1071/D_Dalton_Alexandraa200904.pdf;s equence $=1$ (last visit October 12, 2016).

${ }^{3}$ C. Sargent, and L. Gulbas, Situating Birth in the Anthropology of Reproduction, in A CoMPANION TO MedicAl ANTHRopology (M. Singer, P. Erickson, Eds., Blackwell, Oxford, UK. 2011) doi:10.1002/9781444395303.ch14.

${ }^{4}$ M. Breckinridge, Wide Neighborhoods: The Story of the Frontier Nursing Service (Louisville, KY: The University Press of Kentucky 1981).
} 
believed that nursing was a trusted profession and retained nursing along with midwifery in the Frontier model of care.

British midwifery was professionalized in 1881 with the founding of the Midwives Institute which became the Royal College of Midwives in $1941 .^{5}$ In the post-World War II British model, registered nurses studied another year to become midwives. British midwives provided prenatal care, attended home and hospital births, and visited mother and new-born at home for 28 days following the birth. They provided this care autonomously under their own registration and filled the niche of the physician in prenatal care, labor and birth care, and post partum care of the mother and new born. British births moved from home to hospital parallel to the American movement and following the institution of the British National Health Service. As births moved into hospitals, British midwives expanded their practice to fill the niche occupied by registered nurses in other areas of medicine. ${ }^{6}$ For example, on medical wards, physicians directed plans of care while nurses provided for the day to day healing needs of patients. In labor and birth wards, midwives both directed plans of care and provided the day to day needs. Midwifery management and day to day care of the motherinfant dyad extended in to the nurseries of the day, the postpartum wards and for 28 days of home visits for mother and baby following hospital discharge. Physicians were consulted for maternal or newborn illness that required medications or when forceps or surgical births were necessary. ${ }^{7}$

Midwifery in the UK grew within the National Health Service's universal access to care system. Educating non-surgical midwives to attend most births is the most economical model as at least $75 \%$ of women will not need a physician for illness during pregnancy or a surgical obstetrician for birth. Most British midwives were and remain salaried employees of the National Health Service. ${ }^{8}$ Responsible to the British people for safe and economical healthcare, the British government changed the basic model of midwifery education from post-nursing study to three year, direct entry nonnursing midwifery in $1992 .{ }^{9}$ This model matched the criteria used by the European Economic Community to standardize professions across the

\footnotetext{
${ }^{5}$ C. Jevitt. The Making of a Midwife: The Cultural Constructions of British Midwifery and American Nurse-Midwifery (1994), http://digital.lib.usf.edu/SFS0040031/00001 (last visit September 5, 2016).

${ }^{6} \mathrm{C}$. Jevitt, The Making of a Midwife: The Cultural Constructions of British Midwifery and American Nurse-Midwifery (1994), http://digital.lib.usf.edu/SFS0040031/00001 (last visit September 5, 2016).

${ }^{7}$ Ibid.

${ }^{8}$ National Health Service. Maternity Statistics-England, 2014-2015: Provider Level Analysis, http://content.digital.nhs.uk/article/2021/WebsiteSearch?productid=19422\&q=episiotomy+rates +2015 \&sort=Relevance\&size $=10 \&$ page $=1 \&$ area= both\#top (last visit October12, 2016).

${ }^{9}$ C. Jevitt, The Making of a Midwife: The Cultural Constructions of British Midwifery and American Nurse-Midwifery (1994), http://digital.lib.usf.edu/SFS0040031/00001 (last visit September 5, 2016).
} 
Community. The numbers of British midwives has decreased from about 35,000 in 1992 to 22,000 in 2015, with 2,000 vacancies posted across the UK. ${ }^{1011}{ }^{12}$ Like the United Kingdom, Chinese midwifery professionalized through increased education.

\section{Chinese Midwifery: From Tradition to Western InfLUENCE}

China has a thousand year history of assisted birth. Wenpo, an individual with extensive experience supporting pregnancy and birth, was the earliest name for midwife. The wenpos did not have formal medical education and were seen as dirty and unsafe, placing them low in social stature.

The first female medical college in China with a maternity ward was established in Guanzhou City in 1901.The physicians were dedicated to improving the health of women in the community. The Yale-China Association helped to establish the Xiangya School of Nursing in 1911. The School had two majors: nursing and midwifery. Xiangya School of Nursing is one of the earliest midwifery education programs in China. ${ }^{13}$

Yang Chongrui established the first advanced midwifery technical school in Beijing in 1929 after attending Johns Hopkins University as a visiting fellow. This Beiping First National Midwifery School had two aims. First, re-training lectures were opened for the wenpos to standardize education, measure education by exam and certify the midwives. Few wenpos were able to pass the exam and obtain the midwifery certificate. The second aim was to develop midwives capable of advanced practice. Yang Chongrui set completion of middle school as an admission standard. Between 1929 and 1939, the midwives completed 133,037 outpatient clinic visits, attended 33,000 births in the hospital and 13,448 at home. ${ }^{14}$ Additional midwifery schools were established in Tianjing, Wuhan and Hangzhou. The Beiping First National Midwifery School closed in 1954.

The Chinese government published midwifery laws and rules starting

\footnotetext{
${ }^{10}$ Ibid.

${ }^{11}$ National Health Service. Maternity Statistics-England, 2014-2015: Provider Level Analysis, http://content.digital.nhs.uk/article/2021/WebsiteSearch?productid=19422\&q=episiotomy+rates +2015 \&sort=Relevance\&size $=10 \&$ page $=1 \&$ area=both\#top (last visit October12, 2016).

${ }^{12}$ Royal College of Midwives. State of maternity services report 2015, https://www.rcm.org.uk/sites/default/files/RCM\%20State\%20of\%20Maternity\%20Services\%20Report \%202015.pdf (last visit October13, 2016).

${ }^{13}$ Z. Lvmeiyi, Chinese Introduction and Promotion of the New-Way Laboring, 9 SHANXI NORMAL UNIVERSITY ACADEMIC JOURNAL 83-87 (2007).

${ }^{14}$ Wangyong, Chinese Modern Midwifery Education Foundation: Yangchongrui \& Beiping First National Midwifery School, 22(6) TAIANJIN JouRNAL OF NuRSING (2014).
} 
in 1928. ${ }^{15}$ Midwives had formal education and were certified. The law defined midwifery scope of practice and outlined the different responsibilities between midwives and obstetricians. ${ }^{16}$ Midwifery was an independent profession, separate from nursing and obstetrics, trusted by women. Independent midwifery greatly expanded between 1928 and 1949 with 13,900 midwives certified. ${ }^{17}$ These certified midwives were mostly found in large cities with the wenpos still the major birth attendants in suburban and rural areas. Unlike China, where midwifery developed within urban areas, nurse-midwifery in the US developed in rural areas where there were few obstetricians.

\section{AdAPting the BRItish Midwifery MODEl to AMERICAN CUlture}

During the 1940s and 1950s, nurse-midwives in New York, Kentucky, Alabama and New Mexico and a few other states followed women needing care as US births moved from home to hospital. ${ }^{18}{ }^{19}$ In the fee for service model existing during the development of US nurse-midwifery, nursemidwives, like obstetricians, had to attend numbers of patients and provide diverse services to earn their income by billing for services. This coupled with the dearth of obstetricians in the rural US, pushed expansion of nursemidwifery skills to replicate those of US obstetricians. Unfamiliar with European autonomous midwives, US health administrators and policymakers constrained the growth of nurse-midwifery by viewing nursemidwives as physician assistants. In an organizational model that persists to this day, US nurse-midwives provided prenatal care and followed women into hospitals to direct care and attend the birth while registered nurses provided the day to day care on labor, nursery and postpartum units. US nurse-midwives often followed the practices of physicians to be accepted into hospital practice, such as using inhaled anesthetics during labor, pudendal anesthesia and episiotomies.

The American College of Nurse-Midwives (ACNM) founded in 1955 was the first national organization to represent nurse-midwives. ${ }^{20}$ The

\footnotetext{
${ }^{15}$ Chemingguang, Chinese Historical Health Laws and Regulations (Shanghai, China: Shanghai Medical University Press, 1996).

${ }^{16}$ Ibid.

${ }^{17}$ Chenhaifeng, History of China's Health Care (Shanghai, China: Shanghai Science and Technology Press, 1993).

${ }^{18}$ L. Ettinger, Nurse-Midwifery: The Birth of A New American Profession (NY: Elsevier Publishers, 2006).

${ }^{19}$ J. RoOKS, Midwifery AND Childbirth In AMERICA (Philadelphia, PA: Temple University Press, 2005).

${ }^{20} \mathrm{Ibid}$.
} 
ACNM defined the scope of practice through its document, Core Competencies for Basic Midwifery Practice. ${ }^{21}$ The Core Competencies divide practice into domains that include antenatal care, intrapartum care, postpartum care, newborn care and gynecology among others. Specific skills and competencies are listed within each domain. The Core Competencies are used by professional organizations and state and federal government agencies to define midwifery practice.

From the 1930s through the 1980s, opposition to nurse-midwifery practice was almost universal among US physicians and maternal-child nurses, who felt that nurse-midwives were practicing medicine. The most frequent reason for hospitalization among women aged 12-40 is childbirth. ${ }^{22}$ Obstetricians had anesthesia, forceps, surgery, blood transfusions and antibiotics to convince women that their scientific practice could produce better births. If nurse-midwives could care for women safely, physicians stood to lose economic and social power. Accustomed to healthcare hegemony, organized medicine worked to constrain nurse-midwifery expansion by regulating state practice laws, demanding midwifery supervision by physicians, passing anti-home birth laws, outlawing prescriptive authority for midwives and denying midwives access to hospital practice. In spite of medical opposition by 1980, nurse-midwifery practice was legal in all 50 states and US territories and by 2000, nurse-midwives had some form of prescriptive authority in all states. ${ }^{23}$

New York's Maternity Center Association brought Dr. Grantly DickRead to teach prepared childbirth to its midwives and physicians in $1947 .^{24}$ Dick-Read taught that fear in birth caused tension that caused pain, causing more fear in an escalating cycle. Conditioned relaxation was used to cope with pain in labor. Instead of receiving twilight sleep and being strapped to delivery tables, women using the Dick-Read method were active participants in their births.

Nurse-midwives, who had emigrated from Europe or practiced outside

\footnotetext{
${ }^{21}$ American College of Nurse-Midwives, Core Competencies for Basic Midwifery Practice (2012), http://www.midwife.org/ACNM/files/ACNMLibraryData/UPLOADFILENAME/000000000050/Core \%20Comptencies\%20Dec\%202012.pdf (last visit September 9, 2016).

${ }^{22}$ Healthcare Cost and Utilization Project 2013, Most Frequent Conditions in US Hospitals 2010, http://www.hcup-us.ahrq.gov/reports/statbriefs/sb148.pdf (last visit October3, 2016).

${ }^{23}$ National Center for Workforce Analysis, Bureau of Health Professions, Health Resources and Services Administration. A Comparison of the Changes in Professional Practices for Nurse Practitioners, Physician Assistants and Certified Nurse-Midwives 1992-2000, $\mathrm{http} / / /$ bhpr.hrsa.gov/healthworkforce/supplydemand/nursing/comparechange19922000.pdf (last visit July27, 2015).

${ }^{24}$ L. Ettinger, Nurse-Midwifery: The Birth of A New American Profession (NY: Elsevier Publishers, 2006).
} 
of the US, knew midwifery support of physiologic birth and re-introduced these practices into the US. Women's choice in birth practices, judicious use of technology, and support of physiologic birth became core values in the emerging US nurse-midwifery model.

US nurse-midwives joined women in opposing physician led, medicalized birth. This union led to the proliferation of many childbirth innovations opposed to the medical model of care: Unmedicated birth, family centered birth, home-like hospital birth rooms, mother-baby rooming in, early hospital postpartum discharge, and a resurgence in breast feeding knowledge and support. US nurse-midwifery was a culture of resistance to medicalized obstetrics. ${ }^{25}$ American midwifery was the repository of knowledge related to physiologic birth and low technology perinatal care. Nurse-midwives believed that women had the right to choose the style and place of their births and worked within established biomedicine to make these options available. Midwifery journal articles, educational workshops and educational program curricula refined and promoted low technology birth support to resist the medicalization of birth.

An example of this resistance was nurse-midwifery's refusal to participate in non-evidence-based, ritualized medical treatments such as labor enemas, perineal hair shaves and episiotomies. According to Frankman and Wang, the rate of episiotomy with all US vaginal deliveries decreased from $60.9 \%$ in 1979 to $24.5 \%$ in $2004 .{ }^{26}$ This drop in episiotomy rate follows women's demands for more natural births and practicing nursemidwives having the skills to assist a birth with few perineal lacerations. In 2010-11, only $8.3 \%$ of British vaginal births had an episiotomy. ${ }^{27}$ The US/UK discrepancy is explained by the number of vaginal births attended by midwives: Almost $85 \%$ in the UK and approximately $12 \%$ in the US. ${ }^{28} 29$ During the 1980s, many US academic centers hired nurse-midwives to provide care on teaching units and teach new obstetricians physiologic birth skills. Increased numbers of nurse-midwives teaching in academic medical centers is positively related to the decreased use of episiotomies in the US.

\footnotetext{
${ }^{25}$ C. Jevitt, The Making of a Midwife: The Cultural Constructions of British Midwifery and American Nurse-Midwifery (1994), http://digital.lib.usf.edu/SFS0040031/00001 (last visit September 5, 2016).

${ }^{26}$ E. Frankman, L. Wang, C. Bunker, and J. Lowder, Episiotomy in the United States: Has Anything Changed?, 200(5) AMJ OBSTET GYNECOL_573.e1 (2009). doi:10.1016/j.ajog.2008.11.022.

${ }^{27}$ Health and Social Care Information Centre 2011, NHSMaternityStatistics-England, 2010-2011, http://www.hscic.gov.uk/pubs/maternity1011 (last visit July 27, 2015).

${ }^{28}$ American College of Nurse-Midwives (2016), Essential Facts about Midwives, http://www.midwife.org/Essential-Facts-about-Midwives (last visit October 12, 2016).

${ }^{29}$ Royal College of Midwives, State of Maternity Services Report 2015,

https://www.rcm.org.uk/sites/default/files/RCM\%20State\%20of\%20Maternity\%20Services\%20Report \%202015.pdf (last visit October 13, 2016).
} 
US nurse-midwives also resisted the labor-numbing effects of epidural analgesia which was the obstetrical analgesia of choice by 1990. A 2011 brief from the National Vital Statistics Reports surveyed 27 states finding that $61 \%$ of women used epidural anesthesia for labor pain relief. ${ }^{30}$ Nursemidwives learned to manage labors using epidural analgesia but resisted its use due to complications such as lack of mobility for the mother, obliteration of the urge to push, and an increase in cesarean birth. Epidural analgesia added expense to labor as it is managed by anesthesiologists or nurse anesthetists, prolongs labor using more nursing time, and requires continues fetal monitoring. As the popularity of epidural analgesia spread, nurse-midwives maintained traditional British midwifery skills in low technology birth support to be able to offer women choices for coping with labor including acupressure, hydrotherapy, and position changes.

\section{INCREASING THE SCOPE OF US MIDWIFERY PRACTICE}

Approximately 750 nurse-midwives had been educated in US programs by $1963 .{ }^{31}$ US nurse-midwifery programs added the provision of birth control methods during the post-partum period during the early 1970s, following the judgment in Eisenstadt $v$. Baird that legalized birth control for all Americans in $1972 .{ }^{32}$ According to the science of the time, women needed health screening physical exams with Pap smear cervical cancer screening before the prescription of birth control. US nurse-midwives expanded practice to include well-woman physical exams during the late 1970s and early 1980s. Provision of birth control methods and well woman gynecology care was added to the ACNM Core Competencies for Basic Midwifery Practice during that era. ${ }^{33}$ While British midwifery, and that of other European nations, remained tied to perinatal care, American nursemidwifery was incrementally assuming the scope of practice of obstetricians and gynecologists in the care of health women (Figure 1).

\footnotetext{
${ }^{30}$ M. Osterman, and J. Martin, Epidural and Spinal Anesthesia Use During Labor: 27-State Reporting Area (2008) Centers for Disease Control, 59(5) NATIONAL Vital Statistics Reports (2011), http://www.cdc.gov/nchs/data/nvsr/nvsr59/nvsr59_05.pdf (last visit July 27, 2015).

31 J. ROOKS, MidwIFERY AND CHILDBIRTH In AMERICA (Philadelphia, PA: Temple University Press 2005).

${ }^{32}$ United States Supreme Court, Eisenstadt v. Baird, 405 U.S. 438 (1972), Argued November 17-28, 1971, Decided March 22, 1972, https://supreme.justia.com/cases/federal/us/405/438/case.html (last visit October 1, 2016).

${ }^{33}$ American College of Nurse-Midwives, Core Competencies for Basic Midwifery Practice (2012), http://www.midwife.org/ACNM/files/ACNMLibraryData/UPLOADFILENAME/000000000050/Core \%20Comptencies\%20Dec\%202012.pdf (last visit September 9, 2016).
} 


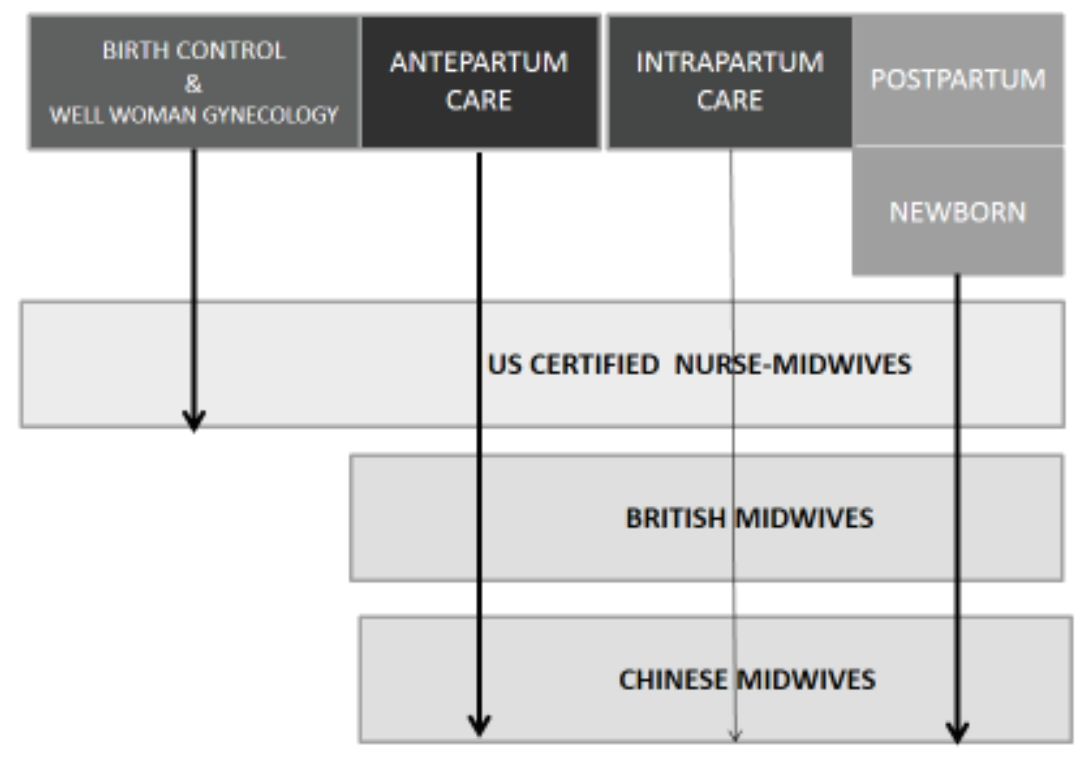

Figure 1 Scope of Practice about 1985, US \& UK \& Chinese Midwifery.

The European midwifery model followed by the United Kingdom has a bachelor's degree in midwifery, separate from nursing, as the entry preparation to basic midwifery practice. ${ }^{34}$ As nurse-midwifery in the US expanded scope of practice, the entry education level was increased to a master's degree in nursing or midwifery to more closely match the educational level of other US healthcare providers. ${ }^{35}$ During this era, the American College of Nurse-Midwives developed a direct entry model of midwifery education, the certified midwife, which did not have nursing education as a pre-requisite and matched the European direct-entry midwifery model of education. ${ }^{36}$ However, instead of educating midwives at the bachelor's degree level as is done in Europe, the certified midwife is educated at the master's level. A certified midwife has the same post-nursing education as a nurse-midwife, takes the same national certification exam and has the same scope of practice. Even with master's degree preparation, a

\footnotetext{
${ }^{34}$ C. Jevitt, The Making of a Midwife: The Cultural Constructions of British Midwifery and American Nurse-Midwifery (1994), http://digital.lib.usf.edu/SFS0040031/00001 (last visit September 5, 2016).

${ }^{35}$ American College of Nurse-Midwives. Mandatory Degree Requirements for Entry into Midwifery Practice (2015), http://www.midwife.org/ACNM/files/ACNMLibraryData/UPLOADFILENAME/ 000000000076/Mandatory-Degree-Requirements-June-2015.pdf (last visit October 13, 2016).

${ }^{36}$ American College of Nurse-Midwives, Midwifery/Nurse-Midwifery Education and Certification in the United States (2016), http://www.midwife.org/ACNM/files/ACNMLibraryData/ UPLOADFILENAME/000000000077/Certified-Midwifery-and-Nurse-Midwifery-Education-andCertification-MAR2016.pdf (last visit October 10, 2016).
} 
nurse-midwife could be educated in 3-6 years, much less time than the 4 years of medical school and 4 years of residency for an obstetrician/gynecologist. US federal and state governments are financials supporters of healthcare provider education. Preparing nurse-midwives in the place of obstetricians for general practice is cost-effective.

Nurse-midwives further expanded care during the 1990s following federal support for the education of primary care providers. Initiated during the 1960s by the American Medical Association's Mills Report, the movement called for a primary physician for every individual. ${ }^{37}$ The original intention was for the primary care physician to be a family practice physician. A shortage of generalist physicians, caused in part by physician selection of high revenue generating specialties such as cardiology and orthopedic surgery, delayed the growth of primary care until the nurse practitioner movement started producing primary care advanced practice nurses. Nurse-midwifery expanded scope of practice again to include the provision of primary care for women. ${ }^{38}$ Currently $33.1 \%$ of nurse-midwives include primary care in their clinical practice. ${ }^{39}$ The American College of Nurse-midwives successfully lobbied to be recognized as primary care providers by Medicare and Medicaid and currently lobby for equal payment for work through S.2694 Ensuring Access to Primary Care for Women and Children Act that would be amended to the Affordable Care Act. ${ }^{40}{ }^{41}$ The expansion of midwifery scope of practice into primary care enabled US nurse-midwives to occupy the niche of obstetricians in low risk pregnancy and birth when surgery was not needed but further shifted the model away from British midwifery's scope of practice (Figure 2).

\footnotetext{
${ }^{37}$ S. Petterson, W. Liaw, R. Phillips, D. Rabin, D. Meyers, and A. Bazemore, Projecting US Primary Care Physician Workforce Needs: 2010-2015, 10(6) ANN FAM MED 503-509, Doi: 10.1370/afm.1431 (2012).

${ }^{38}$ American College of Nurse-Midwives, Core Competencies for Basic Midwifery Practice (2012), http://www.midwife.org/ACNM/files/ACNMLibraryData/UPLOADFILENAME/000000000050/Core \%20Comptencies\%20Dec\%202012.pdf (last visit September 9, 2016).

${ }^{39}$ American College of Nurse-Midwives, Essential Facts about Midwives (2016), http://www.midwife.org/Essential-Facts-about-Midwives (last visit October 12, 2016).

${ }^{40}$ D. Brown, S.737-Ensuring Access to Primary Care for Women \& Children Act, 114th Congress (2015-2016) (2015), https://www.congress.gov/bill/114th-congress/senate-bill/737 (last visit October 10, 2016).

${ }^{41}$ American College of Nurse-Midwives, Ensuring Access to Primary Care for Women Children Act (2015), http://www.midwife.org/acnm/files/ccLibraryFiles/Filename/000000005110/ACNMIssue BriefonEnsuringAccesstoPrimaryCareforWomenandChildrenAct.pdf (last visit October 13, 2016).
} 


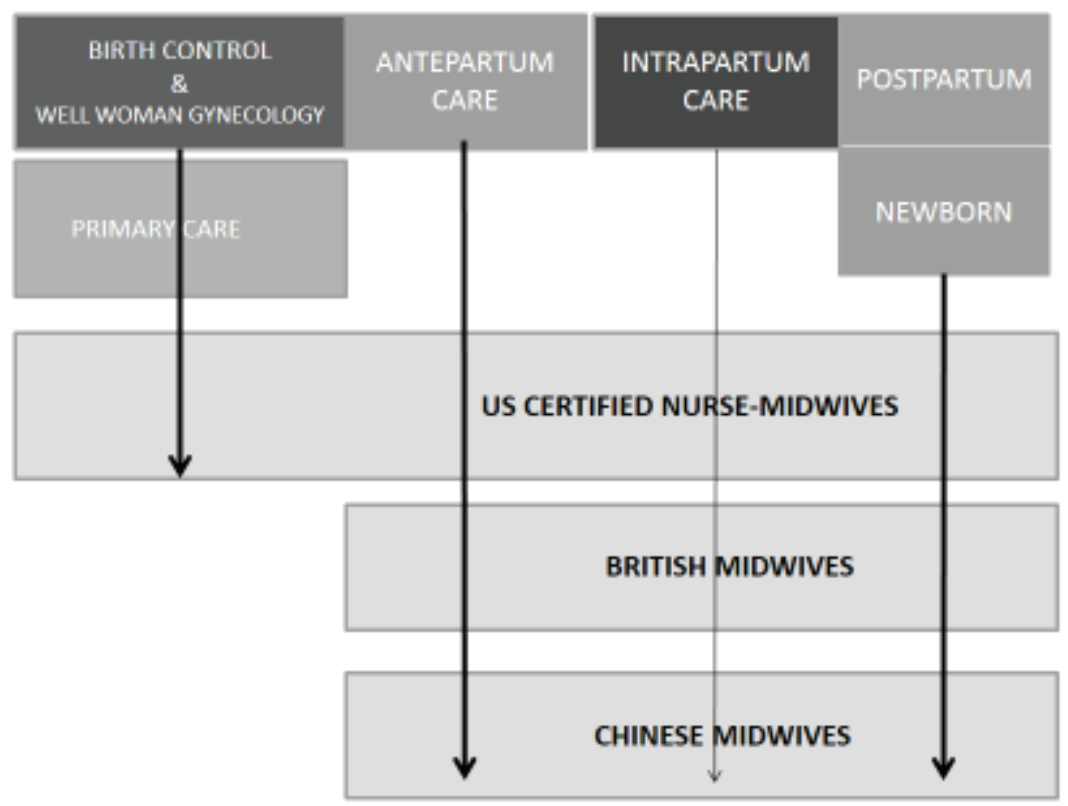

Figure 2 Scope of Practice about 2000, US \& UK \& Chinese Midwifery.

While the scope of British midwifery remains static, the scope of practice for US nurse-midwives is continually expanding. Nurse-midwives routinely provide new-born male circumcision, colposcopy and biopsy, assist in surgery, and provide infertility and urogynecology services. Most recently, the American College of Nurse-Midwives worked collaboratively with the American College of Obstetricians and Gynecologists and the American Institute of Ultrasound in Medicine to support the performance of ultrasound by nurse-midwives. ${ }^{42}$

Nurse-midwifery scope of practice expansion is not pushed only by patient need and provider greed; external forces are important inducers of change in nurse-midwifery. The International Confederation of Midwives (ICM) published a 7th competency for midwives following its 2013 meeting, competency in facilitation of abortion related care. ${ }^{43}$ Spurred by thousands of deaths annually in developing countries due to unsafe abortions and the

\footnotetext{
${ }^{42}$ American College of Nurse-Midwives, Position Statement: Midwives Performance of Ultrasound in Clinical Practice (2012), http://www.midwife.org/ACNM/files/ACNMLibraryData/ UPLOADFILENAME/000000000228/Ultrasound\%20position\%20statement\%20June\%202012.pdf (last visit October 13, 2016).

${ }^{43}$ International Confederation of Midwives, Essential Competencies for Basic Midwifery Practice 2010, revised 2013, http://www.internationalmidwives.org/assets/uploads/documents/CoreDocuments/ ICM\%20Essential\%20Competencies\%20for\%20Basic\%20Midwifery\%20Practice\%202010,\%20revise d\%202013.pdf (last visit October 12, 2016).
} 
lack of abortion providers, international women's health organizations looked to the widespread midwifery profession to fill the clinical gap. With the ICM's 7th Competency, the international scope of midwives increased from providers of perinatal services to providers of arrange of abortion methods. This scope of practice extension mirrored the expansion of US nurse-midwifery into higher technology practice that met the health care needs of women. With few medical students choosing obstetrics as a specialty and fewer learning abortion techniques, midwives and advanced practice nurses in the US expanded scope of practice to fill the service gap (Figure 3). Currently five states permit nurse-midwives to perform medical aspiration and medication abortions while another ten permit nursemidwives to prescribe medication abortions. ${ }^{44}$

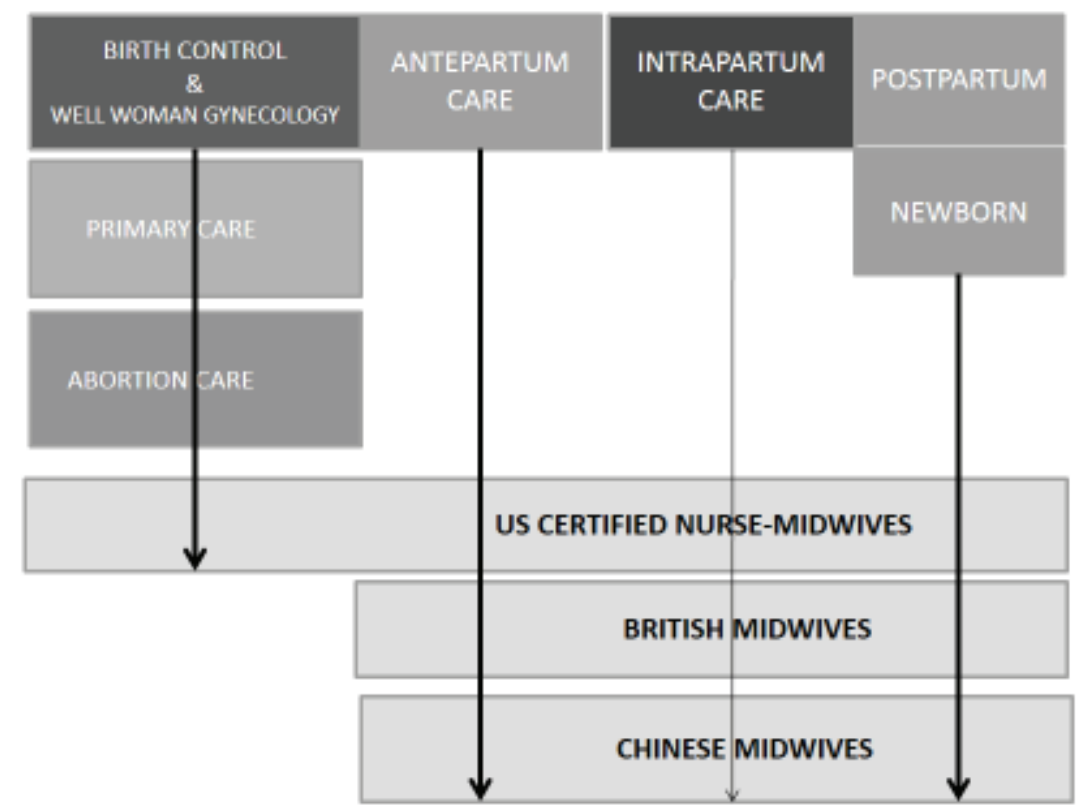

Figure 3 Scope of Practice about 2015, US \& UK Midwifery.

Because midwifery, nursing and medical practice are governed separately by the states, not all states have allowed the expansion of nursemidwifery scope of practice into abortion. It is likely that the ACNM will follow the ICM Competencies for Basic Midwifery Practice (ICM2013) and add abortion provision to the national scope of practice for nurse-midwifery thus prodding additional state boards of nursing and midwifery and state

\footnotetext{
${ }^{44}$ T. Weitz, D. Taylor, S. Desai, U. Upadhyay, J. Waldman, M. Battistelli, and E. Drey, Safety of Aspiration Abortion Performed by Nurse Practitioners, Certified Nurse-Midwives, and Physician Assistants under a California Legal Waiver, 103(3) AmJPuBHEALth 454-461 (2013).
} 
governments to expand the scope of midwifery practice. ${ }^{45}$

\section{RENAisSANCE IN CHINESE MidWIFERy Following RECESSION AND STAGNATION}

The Chinese Cultural Revolution began during the 1960s. Schools of midwifery were closed until the end of the 1970s. Without midwives, registered nurses moved into delivery rooms to receive basic training as birth attendants. In some areas, nurses with basic training used forceps and replaced obstetricians. In many areas, the roles of nursing, midwifery and obstetrics were blurred and unclear. There was a recession with stagnation in education during the 1980s and 1990s resulting in a decline in midwifery that China is still working to overcome.

Starting with the new millennium, nursing education adopted a bachelor's degree entry level with master's degree specialization. Midwifery was re-established at the junior college level. Midwives gradually assumed leadership of maternity wards although nurses and obstetricians continue to deliver babies. On May 5, 2008, the first alliance of Chinese midwives was formed in Qindao by Mengxue. An annual national midwifery conference was initiated.

Zhejiang Province became a group within the International Confederation of Midwives in 2009. China as a nation is not a member state of the ICM. The Advanced Midwifery Education Alliance was established at Beijing University in 2010.

At the end of 2000, nursing became a first class subject like medicine. The Chinese Educational Instruction Committee approved specialties in nursing with midwifery having a strong voice to be an early specialty. Schools of nursing in the Wenzhou Medical University, the Putian University and Southern Medical University have pilot programs to rebuild midwifery with a bachelor's degree entry to practice level. Midwifery students have two years of general nursing education and two years of midwifery specialization. Because these are pilot programs, graduating students receive certificates of nursing but not midwifery.

The national government increased maternal-child health funding starting in 2010, when the 40 year old one-child policy was changed to a two-child policy if both parents were the only children of their parents. A

\footnotetext{
${ }^{45}$ International Confederation of Midwives, Essential Competencies for Basic Midwifery Practice 2010, revised 2013, http:/www.internationalmidwives.org/assets/uploads/documents/CoreDocuments/ ICM\%20Essential\%20Competencies\%20for\%20Basic\%20Midwifery\%20Practice\%202010,\%20revise d\%202013.pdf (last visit October 12, 2016).
} 
universal two-child policy was initiated for all Chinese families in 2015. The roles of advanced practice nurse-midwives and clinical nurse specialists in midwifery are being promoted to prepare for the two child baby boom; however, China has no legal definition of midwifery and this constricts scope of practice. ${ }^{46}$ The government has strong incentive to re-establish the bachelor's degree in midwifery and strengthen the midwifery team. The profession of midwifery must use the opportunity of the Chinese baby boom to strengthen education and practice.

\section{CONCLUSION}

Nurse-midwifery practice is accepted by US registered nurses and obstetricians following almost 100 years of expansion and research that proves the safety of midwifery care. Nurse-midwives attend $12 \%$ of all US vaginal births. ${ }^{47} \mathrm{~A}$ model for nurse-midwives with advanced practice skills that includes prescription of birth control methods, basic gynecological care and primary care of women, has been developed in the US (Figure 3). Advanced practice nurse-midwives in the US can be educated in three years' time as opposed to 4 years of medical school and 4 years of surgical residency for obstetrician/gynecologists. Educating nurse-midwives to provide a broad range of women's health care is cost-effective education. China could use the US nurse-midwifery model to expand the scope of practice of nurse-midwives in China, thus ameliorating the provider shortage associated with the Chinese baby boom.

\footnotetext{
${ }^{46}$ International Confederation of Midwives, High Level Forum on Midwifery Development in China (2016), www.internationalmidwives.org/new/?nid=370 (last visit October 3, 2016).

${ }^{47}$ American College of Nurse-Midwives, Essential Facts about Midwives (2016), http://www.midwife.org/Essential-Facts-about-Midwives (last visit October 12, 2016).
} 